Biochem. Lett., Vol. 5, PP. 32-55 (2009)

\title{
ANTIOXIDANTS AND CDDP-INDUCED NEPHROTOXICITY
}

\author{
Kh.A.AI-Nageh and N.A.Al-Nageh \\ Faculty of Medicine, AlFateh University for \\ Medical Sciences, Tripoli
}

\begin{abstract}
ABSRACT
Cis-dichlorodianunineplatinum(II) (cisplatin (CDDP)) is one of the most effective antitumor agents currently available for cancer therapy. I lowever, its clinical use has been limited by its severe side effects, especially nephrotoxicity. To evaluate the effect of radical scavengers on CDDP nephrotoxicity in rats, $C D D P$ and Vitamin $C$ were given intrapcritoneally. Remarkable protective effects o1' Vitamin $C$ against nephrotoxicity of ${ }^{\prime}$ CDDP were observed when Vitamin $C$ and GSII were administered to rats before or with CDDP injection. Vitamin $C$ which has radical scavenging effect directly reduced nephrotoxicity of CDDP in vivo. Thus, it seems that free radical is the cause of CDDP nephrotoxicity. Also, combination treatment did not reduce anticancer activity of CDDP. The present results indicate that Vitamin C, and/or GSH when there were given before or with CDIII', may provide protection against CDDP nephrotoxicity without reducing anticancer activity. The aim of the present study was to investigate whether or not the renal antioxidant system plays also an important role in renal damage induced CDDP $(2 \mathrm{mg} / \mathrm{kg}$ intrapcritoneally at a single does in rats). In order to elucidate it, serum creatininc and urea levels, renal glutathione and thiobarbituric acid-reactive substances (TBARS) content, as well as renal catalase (CAT), superoxide dismutase (SOD) and glutathione peroxidase (GSHpx) activities were measured in the kidney homogenates and additionally of gene expression of GSHpx and glutathione reductase (GRD) were determined.
\end{abstract}


AI-Nageh, Kh.A. \& Al-Nageh, N. A..

\section{INTRODUCTION}

Cancer is one of the most dreaded diseases and currently taking the heaviest toll of human lives, with distant hope of finding an effective cure unless detected and treated in early stages. Chemotherapy and radiotherapy are the most common modalities of cancer treatment. CDDP is currently one of the most important chemotherapcutic drugs used in treatment of a wide range of solid tumors - head, neck, ovarian and lung cancers. However, the clinical usefulness of this drug is limited due to nephrotoxicity induction, a side effect that-may produced in various animal models. CDDP gets accumulated in the tubular epithelial cells of proximal kidney tubule, causing nephrotoxicity, characterized by morphological destruction of infra cellular organelles, cellular necrosis, loss of microvilli, alterations in the number and size of the lysosomes and mitochondrial vacuolization, followed by functional alterations including inhibition of protein synthesis, GSII depletion, lipid peroxidation and mitochondrial damage (Joy, 2008).

CDDP is one of the most effective chcmotherapeutics against a wide range of cancers including testicular, ovarian, bladder, and neck. It is also used in the management of endometric cancer, nonsmall lung cancer, malignant melanoma, penile cancer and adrcnocorticol carcinoma (Santos et al., 2007 and Martins et al., 2008). However, its therapeutical use is limited by its severe toxic side effects, namely nephrotoxicity (Servais et al., 2008). Although nephrotoxicity is the major limiting factor in its chemotherapeutic use (Servais et al., 2008), liver toxicity may occur when CDDP is administered at high doses (Martins et al., 2008). Moreover, recent studies demonstrated that CDDP induces mitochondria) oxidative damage and apoptosis in rat liver, thus, suggesting mitochondria as a target to the hepatotoxicity of this drug (Santos et al., 2007 and Martins et al., 2008). The exact mechanism by which CP produces renal damage is unknown. After a single dose of $\mathrm{CP}$, there is 
referential sequestration of the drug in the kidneys, liver, intestine, and testes, with concentrations in the kidneys reaching levels higher than 37 times those of plasma (Sheikh -Hamad, 2008).

CDDP-DNA crosslink's causes cytotoxic lesions in tumors and other dividing cells. DNA damaging agents usually have less toxicity in non proliferating cells, yet the quiescent proximal tubule cells are selectively damaged by CDDP. The mechanism for this renal cell injury has been the focus of intense investigation for many years, and recent studies suggest that inflammation, oxidative stress injury, and apoptosis probably explain part of this injury. Understanding the mechanisms) for this side effect should allow clinicians to prevent and/or treat this problem better and provides a model for investigating drug-induced nephrotoxicity in general (Schrier et al., 2004). Morphologic changes after CDDP-induced kidney injury are most prominent in S3 segments of proximal tubules, where loss of brush border membrane, cell swelling, nuclear condensation, and focal areas of tubular cell apoptosis and necrosis are seen (Sheikh Hamad et al., 2004).

Oxidative stress injury is actively involved in the pathogenesis of CDDP - induced acute kidney injury. Reactive oxygen species (ROS) directly act on cell components, including lipids, proteins, and DNA, and destroy their structure. ROS arc produced via the xanthine-xanthine oxidase system, mitochondria, and NADPH oxidase in cells. In the presence of CDDP, ROS are produced through all these pathways and are implicated in the pathogenesis of acute CDDP-induced renal injury (Kawai et al., 2006). CDDP induces glucose-6- phosphate dehydrogenase and hexokinase activity, which increase free radical production and decrease antioxidant production (Yilmaz et al., 2004). It increases intracellular calcium level which activates NADPH oxidase and to stimulates ROS production by damaged mitochondria (Kawai et al., 
2006). Super-oxide anion $\left(\mathrm{O}_{2} \bullet\right)$ (Davis et al., 2001), hydrogen peroxide $\left(\mathrm{H}_{2} \mathrm{O}_{2}\right)$ (Kadikoylu et al., 2004), and hydroxyl radical $(\bullet \mathrm{OH})$ (Shino, et al., 2003), are increased in CDDP-treated kidneys. These free radicals damage the lipid components of the cell membrane by peroxidation and denature proteins, which lead to enzymatic inactivation. Free radicals can also cause mitochondria) dysfunction. Antioxidant enzymes are inhibited by CDDP, and renal activities of SOD, glutathione peroxidase, and CAT are significantly decreased (Badary et al., 2005). Antioxidants melatonin, (Sewer, et al., 2000), vitamin C (Kadikoylu et al., 2004) and vitamin $E$ have been shown to prevent CDDP-induced acute nephrotoxicity (Weijl, et al., 2004).

Agents such as SOD, dimethyl thiourea and GSH have been shown to reduce the degree of renal failure and tubular cell damage when administered simultaneously with CDDP in rats (Sadzuka et al., 1992). Much attention has been given to the possible role of dietary antioxidants in protecting the kidney against CDDP induced nephrotoxicity. There is a large body of evidence on the chemoprotecting activities of vit.C, E., curcumin, selenium, bixin and other dietary components that scavenge free radicals induced by exposure to CDDP (Antunes et al., 2001).

It is well established that CDDP forms platinum-DNA adducts that initiate tumor cell death (Brabec and Kasparkova, 2002; Wang and Lippard, 2005) where N7 of neighboring and intrastrand purines is the preferred binding site (Fichtinger-Schepman et al., 1987). Such CDDP-DNA adducts initiate DNA fragmentation and apoptosis (Henkels and Turclri, 1997). The cytotoxic effect of CDDP when bound to targets other than DNA may also be important. For instance, 

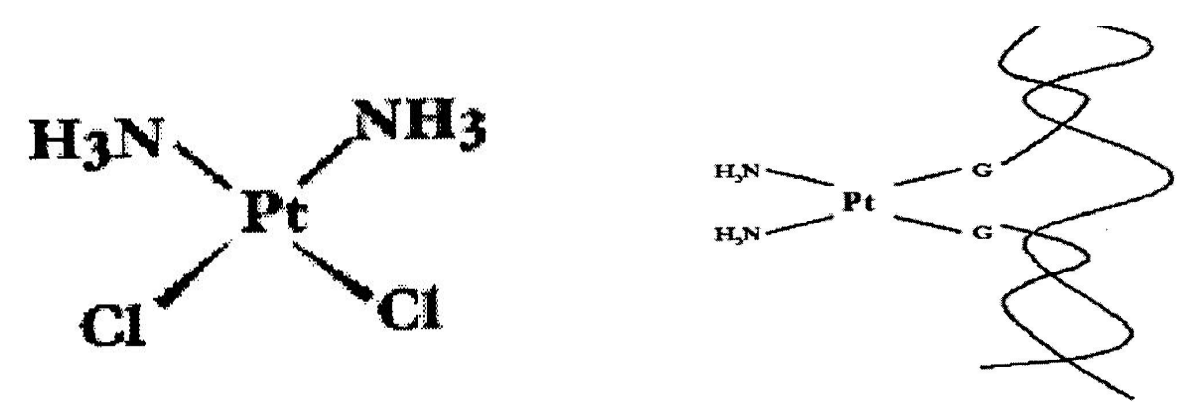

Chemical structure of CDDP and its proposed intraction with DNA

The most common adverse effect limiting the efficacy of this drug is nephrotoxicity which develops primarily in the S3 segment of the proximal tubule. Although the exact mechanism of CDDPinduced nephrotoxicity is not well understood, but according to the previous results, some mechanisms arc involved such as: depletion of sulfl7ydryl ( $\mathrm{SH})$ groups, impaired anti-oxidant defense system and n1110C11o17dCIaI dysfunction by inhibition of complexes I to IV of the respiratory chain in proximal tubules (Baek et al., 2003).

The enzymes, SOD and GSHpx, in the cells are important components of several naturally occurring antioxidant defense mechanisms to prevent oxidative injury (Weijl et al., 1997). There is also a hypothesis that decreased levels of natural antioxidants vitamins and diminished scavenging enzyme capacity may be responsible for the excess of ROS observed in CDDP -induced toxicity (Antunes et al., 2001). GSH plays an important role in the cellular defense system Against oxidative injury, it is a cofactor for GSHpx, which catalyzes the reduction of hydrogen peroxide to water and oxygen, hence limiting the formation of hydroxyl radical, the highly toxic reactive oxygen species (Hsu et al., 2002). 
AI-Nageh, Kh.A. \& Al-Nageh, N. A..

Vitamin $\mathrm{C}$ is an antioxidant that has been demonstrated to be an effective free radical scavenger (Anderson, 1996) and it has been previously shown that VC successfully reduced the clastogenic effect of many antitumor agents and radiation in in vivo assays (Konopacka et al., 1998) also has in vivo anticlastogenic effects against chromosomal damage induced by CDDP in rodents (Antunes et a1., 1999). Supplementation of the antioxidant vitamin $\mathrm{C}$ and selenium has been reported to inhibit lipid peroxide in various conditions such as CDDP-induced nephrotoxicity (Carry and Frenkel, 2000).

CDDP has been thought to bind to the renal base transport system. Cisplatin induces hypomagnesemia through its renal toxicity possibly by a direct injury to mechanisms of magnesium reabsorption in the ascending limb of the loop of Henle as well as the distal tubule. Cisplatin preferentially accumulates in cells of the S3 segment of the renal proximal tubules and is toxified to form a reactive metabolite intracellularly by hydration. The primary symptoms of cisplatin nephrotoxicity are inhibition of protein synthesis and intracellular GSH and protein-SH depletion, resulting in lipid peroxidation and mitochondrial damage (Badccry et al., 2005). The peroxidation of membrane lipids may account for its nephrotoxicity (Satoh et al., 2005). Available evidence suggests that cisplatin exerts its nephrotoxic effects by the generation of free radicals (Kawai et al., 2006). GSH and protein-SH form the major cellular anti-oxidant defense systems, which control lipid peroxidation. From these pathomechanisms of cisplatin nephrotoxicity, it is clear that the nephrotoxicity of cisplatin involves reactive radicals. Thus the reasonable cellular-protective agents against cisplatin toxicity may have at least some antioxidant properties to prevent GSH depletion and/or scavenge the intracellular reactive oxygen species. 


\section{MATERIAL \& METHODS}

A total of 60 Adult male Sprague-Dalcy rat (200 250g) were used in the experiment. The animals were purchased from the Central Animals House of Faculty of Medicine Zigzag University housed in an environmentally $(\mathrm{t}=25 \mathrm{C} \mathrm{C})$ and air humidity $(60 \%)$ controlled room with a 12-hour light-dark cycle, and kept on a standard laboratory diet and drinking water ad libitum.

Animals were maintained in stainless steel cages in the biochemistry Department under hygienic condition. The rats were acclimatized for 2 days and randomly divided to six groups. Group I was injected with saline intraperitoneally, this group served as control. Groups II were treated with GSH for 15 days and then received CDDP plus GSH for 5 days. Groups III was treated with vitamin $\mathrm{C}$ for 15 days then injected with CDDP plus GSH for 5 days. Groups IV was treated with CDDP plus GSH for 5 days. This group treated with CDDP plus GSH for 5 days. Group V was treated with ('DDP plus vitamin $\mathrm{C}$ for 5 days. Group VI was treated with CDDP only for 5 days.

CDDP was injected i.p. by a dose of $02 \mathrm{mg} / \mathrm{kg}$ body weight, Vit.C was administered orally by gavages by a dose of $250 \mathrm{mg} / \mathrm{kg}$ body weight GSH was Injected i.m. by a dose of $600 \mathrm{mg} / \mathrm{kg}$ body weight according to (Giri et al., 1998; Iusania et al., 2002; and Cascinu, et al., 1995) respectively.

Seven Days post the last injection, food was withheld from all animals for 12 houres before blood collection, blood samples were collected by sacrificing the animals and received into heparinized tubes plasma was harvested by centrifuged of the blood at $3000 \mathrm{rpm}$ for biochemical analysis of urea and creatinine using assay kits, kidneys were removed. Small part was taken from kidney as possible as before rats death, weighted and immediately were kept in liquid 
AI-Nageh, Kh.A. \& Al-Nageh, N. A..

nitrogen until be used for determination of gene expression of $\mathrm{GSH}_{\mathrm{Px}}$ and GRD. One gram of kidney was removed from each animals and they are washed out from contaminated blood with cold water was homogenized in $10 \mathrm{ml}$ of distilled water using electrical homogenizer, centrifuged at $3000 \mathrm{rpm}$ for 15 minutes, the resulting supernatant were collected and used for estimation of GSH, antioxidant enzymes (SOD, CAT and $\mathrm{GSH}_{\mathrm{Px}}$ and MAD levels (Sidhu et al., 2004). Kidney from animals was preserved at $-20^{\circ} \mathrm{C}$ until performing the investigations.

\section{RESULTS}

The results are expressed as mean \pm SEM. Data were analyzed by one-way analysis of variance. Sequential difference among mean were calculated at the level of $\mathrm{P}<0.05$, using Tukey contrast analysis as needed.

The internal control gene showed almost stable pattern of expression in the kidney tissues of male rats in treated and control groups.

The level of gene expression of GSHPX and GRD were decrease in kidney homogenate of all groups treated with CDDP, this decrease is of great degree in the group treated with CDDP only but was of lesser degree in the groups treated with GSH or Vit. C plus CDDP that may represent their cure effect in the decrease of the effect of CDDP. 

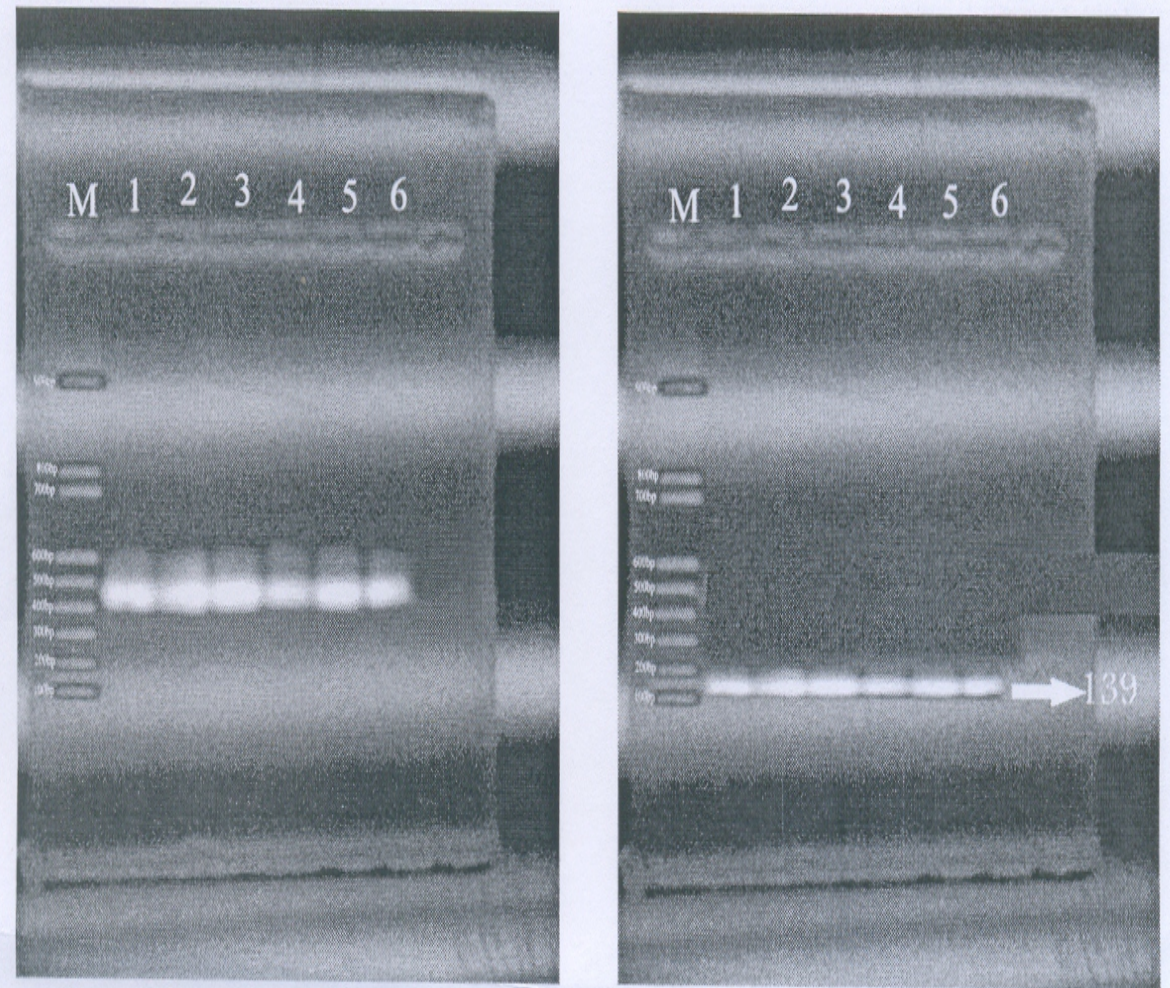

Figure (1\&2): The electrophoretic photograph of Glyceraldhyde 3 phosphate dehydrogenase (GAPDH) (445bp) and Glutathione peroxidase (139bp) mRNA expression in the kidney of male rats. 
AI-Nageh, Kh.A. \& Al-Nageh, N. A..

Table (1): Antioxidant status of rat kidney after treatment with CDDP alone or with vit.C and GSH. Each value represents mean $\pm S D$ of ten rats.

\begin{tabular}{|c|c|c|c|c|c|c|c|}
\hline Group & urea & creatinine & mda & $($ (GSHPX) & gsh & CAT & sod \\
\hline Control & $\begin{array}{l}34.42 \\
\pm 2.1^{d} \\
\end{array}$ & $\begin{array}{l}0.856 \pm \\
0.088^{\circ}\end{array}$ & $\begin{array}{l}2.53 \pm \\
0.144^{c}\end{array}$ & $\begin{array}{l}0.308 \pm \\
0.055^{\mathrm{a}}\end{array}$ & $\begin{array}{l}51.11 \\
\pm 1.7^{\text {ab }}\end{array}$ & $\begin{array}{c}248.8 \pm \\
13.2^{\mathrm{a}}\end{array}$ & $\begin{array}{c}72.96 \pm \\
2.8^{8}\end{array}$ \\
\hline $\begin{array}{l}\text { Glutathione treated for } 15 \\
\text { days then treated with CDDP } \\
\text { and glutathione for } 5 \text { days }\end{array}$ & $\begin{array}{l}119.75 \\
\pm 7.6^{6}\end{array}$ & $\begin{array}{l}2.38 \pm \\
0.26^{b c}\end{array}$ & $\begin{array}{l}2.73 \pm \\
0.112 b c\end{array}$ & $\begin{array}{l}0.206 \pm \\
0.036^{\text {do }}\end{array}$ & $\begin{array}{l}47.1 \pm \\
3.4^{\text {be }}\end{array}$ & \begin{tabular}{|l|}
$250.42 \pm$ \\
$21.69^{\mathrm{g}}$
\end{tabular} & $\begin{array}{c}56.31 \pm \\
5.2^{b}\end{array}$ \\
\hline $\begin{array}{l}\text { Vit. C treated for } 15 \text { days } \\
\text { then treated with CDDP and } \\
\text { glutathione for } 5 \text { days }\end{array}$ & $\begin{array}{l}137,59 \\
\pm 0.99^{\mathrm{a}}\end{array}$ & $\begin{array}{l}2.7 \pm \\
0.45^{b}\end{array}$ & $\begin{array}{l}2.92 \pm \\
0.18^{b c}\end{array}$ & $\begin{array}{l}0.212 \pm \\
0.012 b\end{array}$ & $\begin{array}{l}56.68 \\
\pm 2.4^{\mathrm{a}}\end{array}$ & $\begin{array}{l}235.98 \pm \\
13.35^{2}\end{array}$ & $\begin{array}{c}33.32 \pm \\
7.4^{\mathrm{c}}\end{array}$ \\
\hline $\begin{array}{l}\text { CDDP and glutathine treated } \\
\text { group }\end{array}$ & $\begin{array}{c}69.92 \\
\pm 5.96^{c}\end{array}$ & $\begin{array}{l}1.41 \pm \\
0.05^{\text {de }}\end{array}$ & $\begin{array}{l}3.34 \pm \\
0.25^{b}\end{array}$ & $\begin{array}{l}0.212 \pm \\
0.02^{20}\end{array}$ & $\begin{array}{c}50.18 \\
\pm 2.7 \\
a b c\end{array}$ & $\begin{array}{r}246.12 \pm \\
14.19^{2}\end{array}$ & $\begin{array}{c}35.06 \pm \\
6.7^{7^{\circ}}\end{array}$ \\
\hline $\begin{array}{l}\text { CDDP and vitamin C treated } \\
\text { group }\end{array}$ & $\begin{array}{r}108.7 \\
\pm 7.9^{\mathrm{b}} \\
\end{array}$ & $\begin{array}{l}1.71 \pm \\
0.27^{\mathrm{dd}}\end{array}$ & $\begin{array}{l}3.18 \pm \\
0.26^{b}\end{array}$ & \begin{tabular}{|l}
$0.236 \pm$ \\
0.07 ab \\
\end{tabular} & $\begin{array}{r}55.22 \\
\pm 1.6^{2} \\
\end{array}$ & $\begin{array}{c}225.04 \pm \\
8.67^{\mathrm{a}} \\
\end{array}$ & $\begin{array}{l}41.86 \pm \\
5.86 c\end{array}$ \\
\hline CDDP treated group & $\begin{array}{r}149.25 \\
\pm 3.92^{2} \\
\end{array}$ & $\begin{array}{l}4.58 \pm \\
0.16^{2}\end{array}$ & $\begin{array}{l}4.26 \pm \\
0.16^{2} \\
\end{array}$ & $\begin{array}{c}0.14 \\
\pm 0.014^{b} \\
\end{array}$ & $\begin{array}{l}43.4 \pm \\
1.69^{\circ} \\
\end{array}$ & \begin{tabular}{|c|}
$208.6 \pm$ \\
$3.8^{2}$ \\
\end{tabular} & $\begin{array}{l}15.96 \pm \\
2.67^{d} \\
\end{array}$ \\
\hline F-Test & ** & $* *$ & *** & $\mathrm{N} . \mathrm{S}$ & *** & N.S & $* *$ \\
\hline LSS.D. & 15.4 & 0.773 & 0.626 & $\ldots$ & 6.747 & $\ldots . . . . .$. & 13.92 \\
\hline
\end{tabular}




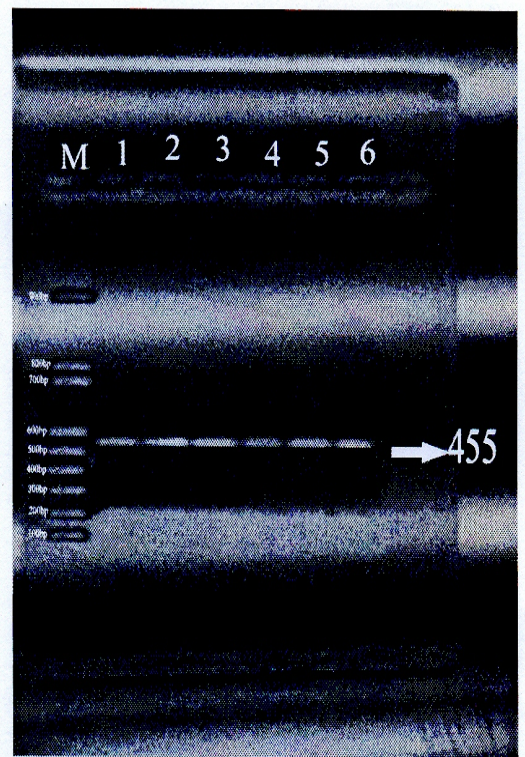

Figure (3): The electrophoretic photograph of Glutathione reductase (554bp) mRNA expression in the kidney tissue of male rats.

M: 100bp-1000bp DNA-ladder

1: Male rats used as control group

2: Male rats treated with GSH for 15 days and then received CDDP plus GSH for 5 days

3: Male rats treated with CDDP plus GSH for 5 days

4: Male rats treated with vitaminC for 15 days then injected with CDDP plus GSH for 5 days.

5: Male rats treated with cispltin plus vitaminC for 5 days.

6: Male rats treated with CDDP only for 5 days.

N.B: Molecular weight where refers to specific amplified product for GAPDH according to the synthesized primer. 
AI-Nageh, Kh.A. \& Al-Nageh, N. A..

Tabel: (2) Analysis of product of mRNA in kidney homogenate of male rats

\begin{tabular}{|l|c|c|c|c|}
\hline \multicolumn{1}{|c|}{ Groups } & Lane & GRD & GSH px & GAPDH \\
\hline \multicolumn{1}{|c|}{ Control } & 1 & $1.568 \mu \mathrm{g}$ & $\mu 2.892 \mathrm{~g}$ & $4.45 \mu \mathrm{g}$ \\
\hline $\begin{array}{l}\text { GSH treated for 15 days, } \\
\text { then treated with CDDP } \\
\text { and GSH for 5 days }\end{array}$ & 2 & $1.298 \mu \mathrm{g}$ & $2.694 \mu \mathrm{g}$ & $4.51 \mu \mathrm{g}$ \\
\hline $\begin{array}{l}\text { Vit: treated for 15 days } \\
\text { then treated with CDDP } \\
\text { and glutathione for 5 } \\
\text { days }\end{array}$ & 3 & $1.165 \mu \mathrm{g}$ & $2.764 \mu \mathrm{g}$ & $4.48 \mu \mathrm{g}$ \\
\hline $\begin{array}{l}\text { CDDP GSH and treated } \\
\text { group }\end{array}$ & 4 & $1.201 \mu \mathrm{g}$ & $2.790 \mu \mathrm{g}$ & $4.39 \mu \mathrm{g}$ \\
\hline $\begin{array}{l}\text { CDDP and vit. C treated } \\
\text { group }\end{array}$ & 5 & $1.246 \mu \mathrm{g}$ & $2.843 \mu \mathrm{g}$ & $4.46 \mu \mathrm{g}$ \\
\hline CDDP treated group & 6 & $1.082 \mu \mathrm{g}$ & $2.398 \mu \mathrm{g}$ & $4.42 \mu \mathrm{g}$ \\
\hline
\end{tabular}




\section{DISCUSSION}

Using an experimental model of CDDP-induced nephrotoxicity in rats, we evaluated the renal activity of the key antioxidant enzymes (SOD, GSH-Px), the glutathione level and TEARS content of tissue as an index of lipid peroxidation. The cytotoxic effects of CDDP are postulated to occur via several mechanisms, including the inhibition of protein synthesis, mitochondria injury and DNA damage (Park et al., 2002). Several studies have now documented the importance of ROS in CDDP-induced nephrotoxicity (Ueda et al., 2000). Oxidative damage of mitochondria might be the initial event causing renal injury by CDDP (Chang et al., 2002). In the present study we assessed in vivo the mitochondria involvement in CDDP-induced nephrotoxicity.

Reports obtained from our study indicate that CDDP increases lipid peroxidation in the treated tissue of rat. The drug is also involved in altering the thiol status of the tissue with concomitant alterations in the enzymatic antioxidants. GSH, SOD and $\mathrm{GSH}_{\mathrm{Px}}$ levels were significantly decreased after CDDP therapy. This effect may be a secondary event following the CDDP-induced increase in free radical generation and/or decrease in lipid peroxidation protecting enzymes. CDDP can cause the generation of oxygen free radicals, such as hydrogen peroxide, superoxide anions and hydroxyl radicals. The hydroxyl radical is capable of abstracting a hydrogen atom from polyunsaturated fatty acids in membrane lipids to initiate lipid peroxidation. These radicals can evoke extensive tissue damage, reacting with macromolecules, such as membrane lipids, proteins and nucleic acids (Emerit $\boldsymbol{e t}$ al., 2001). Moreover, depletion of glutathione may contribute to CDDP -induced lipid peroxidation (Antunes et al., 2000). Thus, an alteration in enzymatic antioxidant 
AI-Nageh, Kh.A. \& Al-Nageh, N. A..

status with increase in lipid peroxidation and nitric oxide indicates that the enzymes play an important role in combating free radical induced oxidative stress on the tissue.

Our results demonstrated that treatment with CDDP $(2 \mathrm{mg} / \mathrm{kg}$, intraperitoneally) induced biochemical and histological signs of renal injury with significant reduction in the activity of SOD and GSHPx. However, several studies demonstrated that CDDP induced acute nephrotoxicity is mediated by depletion of renal GSH and by impaired activity of SOD and GSHpx as well as an increase in renal lipid peroxidation (Kadikoylu et al., 2004). In relation to renal GSH levels, whereas some reports show GSH depletion in acute CDDP nephrotoxicity, others show increased or normal GSH levels under the same experimental conditions.

In the present study, it has been shown that administration of CDDP to rat caused an elevation in plasma creatinine and urea levels. Also, CDDP-induced nephrotoxicity was accompanied by an increase in MDA, reduction of total thiol and GSI-I-Px concentrations in kidney tissue. These results are in accordance with several studies have reported that the alterations induced by CDDP in the kidney functions were characterized by signs of injury, such as increase in products of lipid peroxidation and changes in total thiol concentration in kidney tissue as well as glucose, protein, creatinine and urea levels, in urine and plasma samples (Atessahin et al., 2005).

The impairment of the mitochondria antioxidant defense system (decrease in GSH and NADPH levels, GSH/GSSG ratio, increase in GSSG level) in the CDDP group. This depletion of the antioxidant system could be explained as secondary to the oxidative stress caused by CDDP, or it could explain the oxidative stress itself, in the case of a direct effect of CDDP on enzymatic and non-enzymatic antioxidant system. In fact, it has been reported that CDDP causes a 
decrease in the activities of antioxidant enzymes, including SOD, CAT and GSH-Px (Antunes et al., 2000) and GRD (Kadikoylu et al., 2004) in kidney tissues.

The depletion of GSH and the accumulation of GSSG could, therefore, be explained by the decreased activity of GDR resulting from a direct attack of CDDP. Additionally, there is evidence from both in vivo and cell-culture studies that CDDP is metabolized to a nephrotoxin through a GSH-conjugate interniediate. It has been shown that inhibiting the conjugation of CDDP to GSI-I reduces CDDP nephrotoxicity (Hanigan and Devarajan, 2003). The formation of the Platinum-GSH conjugate could also account for mitochondrial GSH depletion and eventually for the alteration of the redox state in kidney mitochondria.

GSH plays a role in the regulation of $\mathrm{K}^{*}$-channel kinetics (Ruppersberg et al., 1991). This regulation is probably based upon the fast and reversible formation of disulfide bridges between different functional parts of the $\mathrm{K}^{*}$ channel. The depletion of intracellular GSH may have profound effects on the function of cells that are dependent on the normal kinetics of this ion channel. It is also possible that the kinetics of other ion channels is also regulated by intracellular GSH levels. This could be another mechanism by which GSH influences nerve cell function and health. Finally, neuroprotection may be a consequence of the action of GSH on kidney function. Some data support this hypothesis. First, the excretion of CDDP remains constant during treatment, as demon strated by Bohm, et al., (1991). This indicates minimal kidney damage. Otherwise, GSH pretreatment does not influence the pharmacokinetic parameters of CDDP and does not change the bound fraction of CDDP in plasma (Leone et al., 1992).

The decreased concentration of GSH increases the sensitivity of organ to oxidative and chemical injury. The role of GSH, non- 
AI-Nageh, Kh.A. \& Al-Nageh, N. A..

protein thiols in the cells, in the formation of conjugates with electophilic drug metabolites most often formed by cytochrome P450 linked monooxygenase is well stablishcd (Rana et a1., 2002). Reduced renal GSH can markedly increase the toxicity of CDDP. The depletion of GSH also seems to be a prime factor that permits lipid peroxidation in the CDDP treated group. Concomitant treatment of vitamins rendered protection due to the increase in GSH concentration and could protect the renal cells from oxidants attack.

The decreased SOD activity could cause the initiation and propagation of lipid peroxidation in the CDDP treated group. This decreased activity may be either due to loss of copper and zinc, which are essential for the activity of enzyme or due to reactive oxygen species-induced inactivation of enzyme proteins (Ajith et al., 2007). The activity of CAT and GPx also decreased in the CDDP alone treated group, which in turn increased the $\mathrm{H}_{2} \mathrm{O}_{2}$ concentration and enhanced the lipid peroxidation. Hence the concentration of MDA, as a result of lipid peroxidation, increased in the CDDP treated group. Treatment with vitamins prevented the lipid peroxidation by enhancing the renal CAT and GSH-Px activities.

In the present investigation, treatment with Vit $\mathrm{C}$ inhibited the increase in lipid peroxidation induced by CDDP in renal tissue which was measured in terms of MDA, a stable metabolite of the free radical mediated lipid peroxidation cascade. MDA level was increased significantly in CDDP-treated group. VitC has reversed the enhancement of MDA level to a considerable extent, thereby confirming its antioxidant role in CDDP acute renal failure (Hosseinzadeh et al., 2005). The ability of vit.C to significantly decrease renal lipid peroxidation caused by CDDP supports the idea that supplementation with dietary antioxidants could maintain the integrity of lipids in kidney tissue under oxidative stress induced during chemotherapy. 
As Vit.C has been shown to protect against various kinds of injuries and neoplasms involving oxidative stress, it is possible that treatment of animals with Vit.C may attenuate CDDP -induced lipid peroxidation, glutathione depletion, and a decrease in the glomerular filtration rate. (Antunesu et al., 2000). Moreover, Vit.C should be able to diminish DNA damage by reducing radical species directly, decreasing formation of reactive species such as lipid hydroperoxides or preventing radical attack on proteins that repair DNA. Vit.C as an antioxidant can prevent nitrosamine formation, so subsequent formation of some reactive nitrogen species is prevented. Once nitrosamines give rise to reactive nitrogen species, prevention of mutagenic activity by Vit.C is less effective in prevention of DNA damage (Odin, 1997).

A link between Vit.C and DNA repair has been suggested. Intracellular Vit.C calls protect human lymphocytes against oxidative DNA damage in a dose-dependent manner (Cooke et al., 1998). Furthermore, DNA levels of 8 -oxodG, a biological marker of oxidative DNA damage in vivo, decrease significantly after ascorbate supplementation, and this decrease is strongly correlated with increases in the plasma Vit.C concentration (Lenton et al., 1999). These pieces of evidence suggest that antioxidant defences, together with DNA repair, may contribute to give a steady-state level of damage, which represents a minimal risk for the cell. Although interesting, the exact correlation between Vit.C and tile DNA repair machinery has not been extensively investigated.

The present observations support the hypothesis that the mechanism of ncphrotoxicity is related to the depletion of the antioxidant defense system. CDDP treatment has been shown to induce loss of copper and zinc in the kidneys. The decrease in SOD activity in renal tissues following CDDP administration might be due to the loss of copper and zinc (Sharma, 1985). The activity of CAT 
AI-Nageh, Kh.A. \& Al-Nageh, N. A..

and GPx is also found to decrease after CDDP administration resulting in the decreased ability of the kidney to scavenge toxic hydrogen peroxide and lipid peroxides. The results from the present study indicate that the vitamin $\mathrm{C}$ and GSH significantly reduced the depletion of GSH levels and antioxidant enzyme activity in the renal cortex of mice treated with CDDP.

Similar to these studies (St. Clair et al., 1991), have shown that over-expression of MnSOD attenuates the toxic effects of paraquat with no affect on endogenous copper/zinc SOD, CAT, or glutathione peroxidase expression. These results are consistent with our observations with CDDP in that over-expression of MnSOD also demonstrated the role of superoxide radicals in paraquat cytotoxicity. Furthermore, studies in mouse proximal tubular cells have demonstrated that antioxidants, including SOD and CAT, protect these cells from ROS in apoptosis that is induced by either growth factor deprivation (Lieberthal et al., 1996) or CDDP (Lieberthal $\boldsymbol{e t}$ al., 1998).

\section{REFERENCES}

1- Agami, R., Blandino, G., Oren, M. and Shawl, Y. (1999): Interaction of c-Abl and p73alpha and their collaboration to induce apoptosis. Nature (London) 399, 809-813.

2- Antunes Greggi LM, Durin JD, Bianchi AID (2000): Protective effects of vitamin $\mathrm{C}$ against CDDP-induced nephrotoxicity and lipid peroxidation in adult rats: a dosedependent study. Pharmacol. Res 41:405- 411.

3- Antunes LM, Darin JD, Bianchi Nde L., (2001): Effects of the antioxidants curcurnin or selenium on CDDP induced ncphrotoxicity and lipid peroxidation in rats. Pharmacol Res 2001; 43:145-50. 
4- Antunes, G. L. M., Darirr, J D. and Bianchi, M.D. (2000): Protective effects of vitamin $\mathrm{C}$ against CDDP-induced nephrotoxicity and lipid peroxidation in adult rats: a dosedependent study. Pharmacol. Res. 41, 405-411.

5- Atessahin, A., Yilmaz, S., Karahan, I, Ceribasi, A.O. and Karaoglu, A. (2005): Effects of lycopene against CUDP-induced nephrotoxicity and oxidative stress in rats. Toxicology 212: 116123.

6- Badary, OA, Abdel-Maksoud S, Ahmed WA, et al., (2005): Naringenin attenuates CDDP nephrotoxicity in rats. Life Sci; 76 : 2125-35.

7- Baek SH, Piao XL, Lee UJ, Kim HY, Park JH (2006): Reduction of CDDP-induced nephrotoxicity by Ginsenosides isolated from processed Ginseng in cultured renal tubular cells. Biol Pharm Bull; 29:2051-5.

8- Back, S.M., Kwon, C.H., Kim, J.IL, Woo, J.S., Jung, J.S. and Kim, Y.K., (2003): Differential roles of hydrogen peroxide and hydroxyl radical in CDDP induced cell death in renal proximal tubular epithelial cells. J. Lab. Clin. Med. 142: 178-186. Biochem Pharmacol 66. -977-987.

9- Bohm. S., Spalli. G. B.,Di Re. F., Oriana S., Piloni, S., Tedeschi, M., Tognella, S., and Catuui, M. V., Rossi, A., Costanzo, A., Sabatini, S., Levrerv, M., Melirro, G. and Avigliano, L. (2001): Induction of gene expression via activator protein-1 in the ascorbate protection against UV-induced damage. Biochem. J. $356,77-85$.

10- Chang B, Nishikawa M, Sato E, Utsumi K, Inoue M (2002): LCarnitine inhibits CDDP-induced injury of the kidney and small intestine. Arch Biochem Biophys 405:5564.

11- Choie DD, Longnecker DS, del Campo AA., (1981): Acute and chronic CDDP nephropathy in rats. Lab Invest; 44(5):397-402. 
AI-Nageh, Kh.A. \& Al-Nageh, N. A..

12- Conklin KA., (2004): Cancer chemotherapy and antioxidants. J Nutr 134:3201S-3204S.

13- Cooke, M.S., Evans, M.D., Podnrore, LD., Herbert, K.E., Alistry, N., Mistry, P., Hickerehothanr, P.T., Hussieni, A., Griffiths, H.R. and Lrnrec, J. (1998): Novel repair action of vitamin C upon in vivo oxidative DNA damage. FEBS Lett. 363, 363-367.

14- Custodio J.B.A., Moreno A.J.M. and Wallace K.B. (1998): amoxifen inhibits induction of the mitochondrial permeability transition by $\mathrm{Ca}+2$ and inorganic phosphate, Toxicol. Appl. Pharmacol. 152, pp. 10-17.

15- Davis CA, Nick HS, Agarwal A., (2003): Manganese superoxide dismutase attenuates CDDP-induced renal injury: importance of superoxide. J Am Soc Nephrol; 12: 2683-90.

16- Emerit, J., Beaumont, C. and Trivia, F., (2001): Iron metabolism, free radicals and oxidative injury. Biomed Phannacother. 55, 333-339.

17- Hanigan MH and Devarajan P., (2003): CDDP nephrotoxicity: molecular mechanisms. Cancer Ther.; 1:47- 61.

18- Hosseinzadeh, H., Sadegluria, H.R., Ziaee, T., Danaee, A. (2005): Protective effect of aqueous saffron extract (Crocus sativus L.) and crociu, its active constituent, on renal ischemiareperfusion induced.

19- Joy J, Nair CK. (2008): Amelioration of CDDP induced nephrotoxicity in Swiss albino mice by Rubia cordifolia extract. J Can Res Ther; 4:111-5.

20- Kadikoylu G, Bolaman Z, Demir S, et al, (2004): The effects of desferrioxamine on CDDP-induced lipid peroxidation and the activities of antioxidant enzymes in rat kidneys. Hum Exp Toxicol; 23:29- 34. 
21- Kawai Y, Nakao T, Kuninrura N, et al., (2006): Relationship of intracellular calcium and oxygen radicals to CDDP-related renal cell injury. J Pharmacol Sci; 100: 6572.

22- Lenton, K.J., Therriault, H., Fulop, T., Payette, H. and Wagner, I.R. (1999): Glutathione and ascorbate are negatively correlated with oxidative DNA damage in human lymphocytes. Carcinogenesis 20, 607-613.

23- Leone, R., Fracasso, M. E., Soresi. E., Cimino. G., Tedeschi. M., Casloldi, D., Monzani, V., Colvnrbi, L., Usari, T, and Bema Reggi. A. (1992): Influence of glutathione administration on the disposilion of Gee and total platinum in patients after admin istraiion of CDDP. Cancer Chemolher. Pharmacol. 29: 385-390.

24- Levrero, M., De Laurenzi, V., Costanzo, A., Gong, .L, Melino, G. and Wang, J. Y.J. (1999): Structure, function and regulation of p63 and p73. Cell Death Differ. 6, 1146-1153.

25- Lieberthal W, Triaca V, Koh JS, Pagano PJ, Levine JS (1998): Role of superoxide in apoptosis induced by growth factor withdrawal. Am J Plrvsio1275: FG91-F702.

26- Lieberthal W, Triaca V, Levine J (1996): Mechanisms of death induced by CDDP in proximal tubular epithelial cells: Apoptosis vs. necrosis. Am J Phvsio1270: F700-F708.

27- Li-Ping X, Skrezek C, Wand H, Reibe F (2000): Mitochondrial dysfunction at the early stage of CDDP-induced acute renal failure in rats. J Zhejiang Univ Sci 1: 91-96.

28- Martins N.M., Santos, N.A.G., Curt C., Bianchi M.L.P. and Santos A.C. (2008): CDDP induces mitochondrial oxidative stress with resultant energetic metabolism impairment, membrane rigidification and apoptosis in rat liver. J. Appl. Toxicol. 28, pp. 337-344.

29- McGinnes, J. E., Proctor, P. H., Denropoulos, IL B., Hokanson. J. A., and Kirkpatrick. D.S., (1978): Amelioration of 
AI-Nageh, Kh.A. \& Al-Nageh, N. A..

CDDPum nephrotoxicity by orgotein (Superoxide disimilase).Physiol. Chem. Phys., 10: 267-77.

30- Ochiai, T., Ohno, S., Soeda, S., Tanaka, H., Shoyama, Y. and Shimeno, H. (2004a): Crocin prevents the death of rat pheochromyctoma (PC-12) cells by its antioxidant effects stronger than those of $\alpha$-tocopherol. Neurosci. Lett. 362: G1-64.

31- Ochiai, T., Soeda, S.fl., Ohno, S., Tanaka, H., Shoyama, Y. and Shimeno, H. (2004b): Crocin prevents the death of PC-12 calls through oxidative damage in rats. J. Pharm. Pharmaceut. Sci. 8: 387-393.

32- Park MS, De Leon M, Devarajan P (2002): CDDP induces apoptosis in LLC-PKl cells via activation of mitochondrial pathways. J Am Soc Nephrol 13:858-865.

33- Price PM, Yu F, Kaldis P, Aleem E, Nowak G, Sufirstein RL and Megyesi J., (2006): Dependence of CDDP-induced cell death in vitro and in vivo on cyclindependent kinase 2. J Arrr, Soc Neplrro117: 2434-2442.

34- Ran Q, Van Renunen H, Gu M, et al., (2003): Embryonic fibroblasts from Gpx4+/_ mice: a novel model for studying the role of membrane peroxidation in biological processes. Free Radic Biol Med; 35: 1101-9.

35- Rosenberg, B. (1978): Platinum complexes for the treatment of cancer. Interdiscip. Sci. Rev. 3: 134- 147.

36- Ruppersberg. J. P.. Stocker, M., Pongs. O., Heinemann. S. H., Frank. R., and Koerren. M. (1991): Regulation of fast inactivalion of cloned mammalian $1 \mathrm{k}$ (A) channels by cysteine oxidation. Naiure (Loud.), 352: 711-714.

37- Sadzuka Y, Shoji T, Takino Y. (1992): Effect of CDDP on the activities of enzymes which protect against lipid peroxidation. Biochem Pharmacol 1992; 43:1872-5. 
38- Santos N.A.G., Martins N.M., Card C., Bianchi M.L.P. and Santos A.C., (2007): Dinrethylthrourea protects against mitochondrial oxidative damage induced by CDDP in liver of rats. Chem. Biol. Int. 170, pp. 177-186.

39- Satoh, M., Kashihara, N., Fujimoto, S., Horike, H., Tokura, T., Nanrikoshi, T., Sasaki, T. and Makino, H. (2003): A novel free radical scavenger, Edaruhorre, protects against CDDPinduced acute renal damage in vitro and in vivo. J. Pharmacol. Exp. Ther. 305: 1183-1190.

40- Sener G, Satiroglu H, Kabasakal L. (2000): The protective effect of melatonin on CDDP ncphrotoxicity. Fundam Clin Pharmacol 2000; 14: 553- 60.

41- Servais H., Ortiz A., Devuyst 0., Denamur S., Tulkens P.A1 and Mingeot-Leclercq M.P. (2008): Renal cell apoptosis induced by neplrrotaric drugs: cellular and molecular mechanisms and potential approaches to modulation. Apoptosis 13, pp. 11-32.

42- Sharma RP., (1985): Interactions of CDDP with cellular zinc and copper in liver and kidney tissues. Pharmacol Res Commun; 17: 197-206.

43- Sheikh-Hamad D, Cacini W, Buckley AR, Isaac J, Truong LD, Two CC and Kishore BK., (2004): Cellular and molecular studies on CDDP-induced apoptotic cell death in rat kidneY. Arch Toxicol 78: 147-155.

44- Sheikh-Hamad D, Tin:rrrins K and Mali Z., (1997): CDDPinduced renal toxicity: possible reversal by $\mathrm{N}$-acetylcysteine treatment. JAnI Soc Nep/n॰ol 8: 1640-1644.

45- Sheikh-Hamad D., (2008): Cytoplasmic initiation of CDDP. Am J Physiol Renal Physiol., 10-1152.

46- Shino Y, Itolr Y, Kuhota T, (2003): Role of poly (ADP-ribose-) polymerase in CDDPinduced Injury in LLC-PKI cells. Free Radic Biol Med; 35:966-77. 
AI-Nageh, Kh.A. \& Al-Nageh, N. A..

47- Silva, C.R., Greggi Antunes, L.M. and Bianchi, M.D. (2001): Arrtrorrdurrt action of hi-vin against CDDPhrduced chromosome aberrations and lipid peroxidativn in rats. Phcu•muc•ol. Res. 43: 561-566.

48- Souid AK, Tacka KA, Galvan KA, Penefsky HS (2003): Immediate effects of anticancer drugs on mitochondrial oxygen consumption. Sphingomyelinase- ceramide signaling by increasing glutathione synthesis. Neuroclrem. Int. 44: 321-330.

49- St Clair DK, Oberley TD, and Ho YS., (1991): Overproduction of human Mn-superoxidc dismutase modulates parayuat-mediated toxicity in mammalian cells. FEBS Lett 293: 199-203.

50- Stahl, W. and Sies, H. (2003) Antioxidant activity of carotenoids. Mol. Aspects Med. 24: 345-351.

51- Tapiero, H., Townsend, D.M. and Tew, K.D. (2004): The role of carotenoids in the prevention of human pathologies. Biomed. Pharmacother, 58: 100-110.

52- Timothy P. Dalton, Howard G. Shertzer, and Alvaro Prrga (1999): Regulation of gene expression by reactive oxygen. Annual Review of Pharmacology and Toxicology Vol. 39: 67-101.

53- Ueda N, Kaushal GP, Shah SV., (2000): Apoptotic mechanisms in acute renal failure. Am J Med 108: 403-415.

54- Weijl NI, Elsendoorn TJ, Lentjes EG, et al., (2004): Supplementation with antioxidant micronutrients and chemotherapy-induced toxicity in cancer patients treated with CDDP based chemotherapy: a randomized, double-bind, placebocontrolled study. Eur J Cancer; 40: 1713-23.

55- Yilmaz HR, Iraz, M, Sogut S, et al., (2004): The effects of erdosteine on the activities of some metabolic enzymes during CDDP-induced nephrotoxicity in rats. Pharmacol Res; 50:287-90. 